\title{
Assessment and management of resistant hypertension
}

\author{
Raj S. Padwal MD MSc, Simon Rabkin MD, Nadia Khan MD MSc
}

$\mathrm{R}$ esistant hypertension is defined as a blood pressure level above target despite treatment with three optimally dosed, best-tolerated antihypertensive drugs of different classes. ${ }^{1}$ Of the three agents, one should ideally be a diuretic, one a renin-angiotensin system blocker (either an angiotensin-converting-enzyme [ACE] inhibitor or an angiotensin-receptor blocker) and one a dihydropyridine calciumchannel blocker. ${ }^{2}$ Blood pressure controlled with four or more antihypertensive agents is also considered resistant hypertension. ${ }^{1}$

Hypertension affects about 20\% of Canadian adults. ${ }^{3,4}$ The prevalence of resistant hypertension in this patient population varies from $8 \%-12 \%$ in population-based surveys and audits of primary care practices $^{5-7}$ to $11 \%-21 \%$ in specialized clinics. ${ }^{8,9}$ The true prevalence is difficult to ascertain because many studies failed to exclude pseudoresistance (described later). Older age, female sex, black race, excess intake of salt or alcohol, diabetes, obesity, kidney disease and longstanding, poorly controlled hypertension are associated with resistance. ${ }^{1,2}$ The risk of cardiovascular morbidity and mortality is higher among patients with resistant hypertension than among those whose hypertension is well controlled. ${ }^{1,2,10}$ This increased risk is likely mediated by uncontrolled blood pressure, ${ }^{10}$ concomitant comorbidities (diabetes, sleep apnea, obesity) and target organ damage (renal disease, left ventricular hypertrophy and cardiovascular disease)., ${ }^{1,2,9}$

In this article, we review the assessment and management of resistant hypertension, including

\section{Box 1: Evidence for this review}

We searched MEDLINE (1946 through Apr. 21, 2013) using the keywords "resistant hypertension" and "refractory hypertension." We excluded duplicate articles and limited the search to human studies that were published in English. Of 1163 citations screened, we reviewed 187 full-text articles, including 8 randomized controlled trials and 2 consensus guideline statements. We also scanned reference lists to identify additional citations of relevance. emerging therapies. A summary of our literature search is outlined in Box 1. We found few randomized controlled trials (RCTs) and no systematic reviews to guide decision-making. Thus, we have made management recommendations based primarily on expert consensus unless otherwise specified. Most of the studies identified in our literature search examined blood pressure, a validated surrogate outcome, and did not assess morbidity or mortality as outcomes. ${ }^{11}$

\section{Which factors contribute to resistant hypertension?}

Resistant hypertension results from numerous and often simultaneously acting factors (Table 1 and Box 2). Obesity (especially visceral adiposity) and obstructive sleep apnea are the two most prevalent factors, the former found in $50 \%$ of people with resistant hypertension ${ }^{18}$ and the latter in 64\%-83\%..$^{19,20}$ Concurrent use of certain medications or substances can also lead to resistance (Box 2).

Primary aldosteronism, resulting from excess unilateral or bilateral adrenal secretion of aldosterone, is present in $11 \%-20 \%$ of patients with resistant hypertension referred to specialty clinics and is characterized by suppressed renin levels. ${ }^{1,21,22}$ High aldosterone levels are also found in many other conditions, such as obesity, sleep apnea and renal artery stenosis. ${ }^{1,23}$ Elevated aldosterone levels are associated with detrimental cardiovascular physiologic effects, such as
Competing interests:

Raj Padwal has received speaker or consultant fees from Forest Labs,

Medtronic, Abbott Labs and Servier. He has conducted clinical trials with Novo Nordisk and CVRx. No competing interests were declared by Simon Rabkin and Nadia Khan.

This article has been peer reviewed.

Correspondence to: Raj Padwal, rpadwal@ualberta.ca

CMAJ 2014. DOI:10.1503 /cmaj.130764 
oxidative stress, endothelial dysfunction, inflammation and tissue fibrosis. ${ }^{24}$

Elevated activity of the sympathetic nervous system is also a key contributor to resistant hyper- tension. This excess activity is frequently present in primary (essential) hypertension. ${ }^{25,26}$ Increased sympathetic outflow leads to systemic and renal vasoconstriction, hypertrophy and proliferation of

Table 1: Conditions that contribute to resistant hypertension

\begin{tabular}{lll}
\hline Condition Comments & Diagnostic tests
\end{tabular}

\section{Assess in all patients}

Obstructive sleep apnea

Polysomnography is required for a definitive diagnosis.

Medications

See Box 2

Primary aldosteronism (Conn syndrome)

Renal parenchymal disease (glomerulonephritis and other intrinsic renal disease)

\section{Assess in selected patients depending on clinical presentation}

Renovascular disease Computed tomography (CT), magnetic resonance (MR) angiography or arterial Doppler ultrasonography to detect anatomic stenosis. Doppler ultrasonography does not cause contrast nephropathy, but its availability depends on local expertise. Conventional angiography is the gold standard. Renal scanning with captopril can be performed to screen for functional stenosis.

\section{Cushing syndrome}

Thyroid disease

Hypercalcemia

Measurement of ionized or albumin-corrected calcium

Pheochromocytoma

Coarctation of aorta level in serum.

If the syndrome is clinically suspected, measurement of 24-h urine cortisol level or late-night saliva cortisol level, or low-dose dexamethasone suppression test. A positive result in two of three tests is required for diagnosis.

Measurement of thyroid stimulating hormone. If a central cause is suspected, the thyroxine (T4) level should be measured.

Headache, diaphoresis and tachycardia (palpitations) constitute the classic triad of symptoms. Measurement of 24-h metanephrine levels is the initial screening test. Some experts recommend measurement of fractionated plasma metanephrine levels if pretest probability for pheochromocytoma is high (e.g., high-risk familial syndrome). ${ }^{17}$

In young patients, checking for delayed femoral pulses relative to brachial pulses, and reduced blood pressure in the legs relative to pressure in the arms.
Refer patient for testing if their history is suggestive. Activation of the sympathetic nervous system and high aldosterone levels are key drivers of increases in blood pressure. Nocturnal rostral fluid shift (to the head and neck) can increase the severity of sleep apnea. ${ }^{12}$

If feasible, stop all drugs contributing to the elevated blood pressure.

Referral to a specialist may be required. Confirmatory suppression tests include salt-loading (intravenous or oral) and fludrocortisone or captopril suppression. If the result is positive, adrenal imaging and bilateral adrenal venous sampling are performed. Adrenalectomy is used to treat unilateral disease. Bilateral disease is treated with a mineralocorticoid receptor antagonist or an epithelial sodiumchannel blocker.

Referral to nephrology is recommended. A biopsy may be needed.

Fibromuscular dysplasia is typically found in young to middle-aged women, and about one-third of the cases are treated successfully with angioplasty. ${ }^{15}$ The diagnosis should be considered if no other apparent cause of resistant hypertension is present, if a renal bruit is present or if the renin level is high. Atherosclerotic stenosis of the renal artery does not respond well to stenting, and screening is not performed routinely. ${ }^{16}$

If screening results are positive, adrenocorticotropic hormone testing and imaging of the relevant site (pituitary gland or adrenal gland) are required.

Hypothyroidism is associated with elevated diastolic blood pressure, and hyperthyroidism is associated with elevated systolic pressure.

Vasoconstriction and renal dysfunction are the main mechanisms leading to hypertension. Assessment for the underlying cause, including primary hyperparathyroidism, is warranted.

Rarely occurs. Scintigraphy with ${ }^{131}$ iodine $m$-iodobenzylguanidine is used for localization. An $\alpha$-blocker with or without a $\beta$-blocker is the treatment regimen of choice. Surgical referral is indicated for resectable cases.

CT or MR angiography should be performed if screening result is positive. 
vascular smooth muscle cells, left ventricular hypertrophy, endothelial dysfunction, insulin resistance, systemic inflammation, oxidative stress, and sodium and water retention. ${ }^{27}$

\section{How should patients with resistant hypertension be evaluated?}

The exclusion of pseudoresistance is the first step in the evaluation of a patient with resistant hypertension (Figure 1). White-coat effect (present to some extent in up to $40 \%$ of patients with apparently resistant hypertension ${ }^{18}$ ), inaccurate measurement techniques, nonadherence to treatment and a suboptimal medication regimen are common contributors. ${ }^{1}$ Use of 24-hour ambulatory monitoring or self-monitoring at home to document a normal out-of-office blood pressure level rules out white-coat effect. ${ }^{11}$ Manual office-based readings of blood pressure are not accurate in patients with white-coat effect; therefore, doses should be adjusted using out-of-office measurements (repeat ambulatory or home monitoring).

Nonadherence to pharmacologic and nonpharmacologic treatments should be assessed through patient interview; improved adherence reduces blood pressure. ${ }^{1}$ About $40 \%$ of patients with resistant hypertension stop treatment after one year. ${ }^{1}$ If nonadherence to pharmacologic treatment is suspected, electronic prescription records can be reviewed for confirmation. To improve adherence, consensus guidelines recommend combination products to reduce the pill burden, long-acting formulations of drugs taken once daily, self-monitoring of blood pressure and multidisciplinary patient management. ${ }^{1,11}$

After pseudoresistance is excluded and true resistant hypertension is confirmed, an assessment for secondary hypertension should be performed (Table 1 and Box 2). If feasible, medications contributing to the elevated blood pressure should be stopped (Box 2).

\section{What modifications are most likely to be effective?}

\section{Optimizing the existing drug regimen}

Selecting optimal medication combinations at the most effective dosages based on the patient's conditions can improve blood pressure control (Figure 1). Bedtime dosing can lower nocturnal blood pressure by $5.2 \mathrm{~mm} \mathrm{Hg}(p<0.001)$ and potentially reduce mortality and cardiovascular events by $61 \%$ $(p<0.001){ }^{9,42,43}$ However, further trials are needed to confirm these findings in patients with hypertension and in those with resistant hypertension. ${ }^{11}$

\section{Optimizing health behaviours}

Patients with hypertension should be advised to reduce salt intake, participate in regular aerobic exercise, eliminate excessive alcohol intake, maintain a normal body weight and eat a diet based on the Dietary Approaches to Stop Hypertension (DASH) plan. ${ }^{11}$ Aside from salt reduction and aerobic exercise, the evidence base underlying these recommendations is derived largely from studies involving patients with nonresistant hypertension. ${ }^{44}$

In a four-week randomized cross-over trial, 12 patients with resistant hypertension were assigned to a low- $(50 \mathrm{mmol} / \mathrm{d})$ or high$(<250 \mathrm{mmol} / \mathrm{d})$ salt diet for one week, followed by a two-week washout period; the patients then followed the opposite diet for one week..$^{45}$ The low-salt diet reduced systolic blood pressure by $22.7 \mathrm{~mm} \mathrm{Hg}$ (95\% confidence interval [CI] 11.8$33.5 \mathrm{~mm} \mathrm{Hg}$ ) and diastolic blood pressure by $9.1 \mathrm{~mm} \mathrm{Hg}$ (95\% CI 3.1-15.1 mm Hg) compared with the high-salt diet.

In a 10-week RCT, 50 sedentary patients with resistant hypertension were randomly assigned to aerobic exercise (treadmill walking three times weekly) or no exercise..$^{41}$ Patients in the exercise group had significant reductions in systolic and diastolic blood pressure $(6 \pm 12$ and $3 \pm$ $7 \mathrm{~mm} \mathrm{Hg}$, respectively; $p=0.03$ for both) compared with the control group.

\section{Treatment of obstructive sleep apnea}

Limited RCT-level data support the use of continuous positive airway pressure in patients with resistant hypertension. In an RCT involving 75 patients (65\% with resistant hypertension) that compared the use of continuous positive airway

Box 2: Medications and substances that can increase blood pressure

- Alcohol

- Nonsteroidal anti-inflammatory drugs

- Oral contraceptives

- Antidepressants (monamine oxidase inhibitors, certain serotonin reuptake inhibitors and serotonin-norepinephrine reuptake inhibitors)

- Stimulants (amphetamines and cocaine), sympathomimetics and decongestants

- Corticosteroids and anabolic steroids

- Erythropoetin and analogues

- Natural licorice

- Herbal products (e.g., ma huang [ephedra] and bitter orange)

- Chemotherapeutic agents (e.g., tyrosine kinase inhibitors and vascular endothelial growth factor inhibitors) 
pressure with no treatment, no overall betweengroup differences in blood pressure were noted. ${ }^{46}$ However, among patients with resistant hyper-

\section{Exclude pseudoresistance}

- Exclude white-coat effect through the use of 24-h ambulatory monitoring (preferred) or home monitoring of blood pressure

- Exclude nonadherence to drug treatment; if present, optimize adherence

- Stop use of interfering medications (Box 2)

\begin{tabular}{|c|}
\hline $\begin{array}{l}\text { Optimize existing drug regimen* } \\
\text { - Choose agents to address compelling indications, if } \\
\text { present } \\
\text { - Minimize drug costs if finances are influencing } \\
\text { adherence } \\
\text { - Use long-acting agents at appropriate doses } \\
\text { - Include a thiazide or nonthiazide diuretict } \\
\text { - Use a loop diuretic if fluid overload is present } \\
\text { - Use combination products to enhance adherence } \\
\text { - Consider dosing one or more agents at bedtime }\end{array}$ \\
\hline$\downarrow$ \\
\hline $\begin{array}{l}\text { Advise the patient to: } \\
\text { - reduce salt intake to }<2000 \mathrm{mg} / \mathrm{d} \\
\text { - curb excess alcohol intake } \\
\text { - introduce aerobic exercise } \\
\text { - normalize body weight (body mass index }<25 \text {; waist } \\
\text { circumference }<88 \mathrm{~cm} \text { in women and }<102 \mathrm{~cm} \text { in men) }\end{array}$ \\
\hline$\downarrow$ \\
\hline $\begin{array}{l}\text { Evaluate for secondary causes, as indicated } \\
\text { See Table } 1\end{array}$ \\
\hline$\downarrow$ \\
\hline $\begin{array}{l}\text { Consider add-on pharmacotherapy } \\
\text { See Table } 2 \text { for options and indications }\end{array}$ \\
\hline$\downarrow$ \\
\hline $\begin{array}{c}\text { Consider referral to hypertension specialist } \\
\text { Evaluate for device-based treatment }\end{array}$ \\
\hline
\end{tabular}

Figure 1: Approach to the evaluation and management of resistant hypertension. *A standard regimen consists of a long-acting thiazide or nonthiazide diuretic, a renin-angiotensin system blocker (angiotensin-converting-enzyme [ACE] inhibitor or angiotensin-receptor blocker) and a dihydropyridine calcium-channel blocker. tThe most commonly used thiazide diuretic is hydrochlorothiazide, which is widely available in fixed-dose combination products. Nonthiazide diuretics include chlorthalidone and indapamide. Some experts recommend using a nonthiazide diuretic because it is longer acting and more potent than a thiazide diuretic. ¥Aerobic exercise was found to reduce blood pressure by $6 / 3 \mathrm{~mm} \mathrm{Hg}(p=0.03$ for both parameters) among patients with resistant hypertension. ${ }^{41}$ The other health behaviour recommendations listed to optimize health behaviours apply to all patients with hypertension, including those with resistant hypertension. ${ }^{11}$ tension, those who received continuous positive airway pressure had greater reductions in 24-hour ambulatory blood pressure than the controls (systolic -7.6 v. $-0.6 \mathrm{~mm} \mathrm{Hg}, p=0.07$; and diastolic -4.9 v. $0.1 \mathrm{~mm} \mathrm{Hg}, p=0.03) .{ }^{46}$ Although these data should be considered preliminary and will require confirmation, continuous positive airway pressure is already indicated for sleep apnea; thus, it is reasonable to recommend it to patients with concomitant resistant hypertension to help improve blood pressure control.

\section{Add-on therapy}

If blood pressure remains uncontrolled after a diuretic, a renin-angiotensin system blocker and a dihydropyridine calcium-channel blocker have been prescribed and the dosing has been optimized, the use of additional drugs can be considered (Table 2). Mineralocorticoid-receptor antagonists have been the most rigorously studied. Among the other available agents, $\alpha$ - and $\beta$-blockers are also commonly prescribed and have been used as addon drugs in many large-scale clinical trials.

\section{Selecting the add-on drug}

If a compelling indication for a given class of drugs is present (Table 3), an agent from that class is chosen first. ${ }^{11}$ Otherwise, the choice can be made through renin profiling (Table 3 ) or empirically.

\section{Renin profiling}

Using measurements of plasma renin activity as a guide (Table 2), anti-renin agents are prescribed if renin levels are high $(\geq 0.65 \mathrm{ng} / \mathrm{mL}$ per h); otherwise antivolume agents are prescribed. In an open-label RCT involving 77 patients seen in a hypertension specialty clinic (60\% with resistant hypertension), medication adjustment using algorithm-guided renin profiling reduced blood pressure more than usual care (systolic -29 v. $-19 \mathrm{~mm} \mathrm{Hg}, p=0.03$; and diastolic $-13 \mathrm{v} .-11 \mathrm{~mm} \mathrm{Hg}, p=0.3){ }^{47}$

Patient characteristics such as age and race can be used in lieu of renin measurement. ${ }^{48}$ Older patients $(\geq 55 \mathrm{yr})$ and black patients often exhibit low-renin, volume-expanded hypertension and respond best to antivolume drugs. ${ }^{49}$ Younger individuals and white patients usually respond best to antirenin agents. ${ }^{48,49}$ This approach is often used to select initial therapy for treatment-naive patients, but renin profiling is more useful for choosing add-on drugs. ${ }^{50}$

\section{Empiric therapy with mineralocorticoid- receptor antagonist}

Pharmacologic blockade of the mineralocorticoid receptor targets the excess aldosterone commonly present in patients with resistant hyper- 
tension. ${ }^{1,51}$ Spironolactone is most frequently used. Eplerenone, which has fewer sex-hormonedependent adverse effects (e.g., painful gynecomastia and erectile dysfunction), is a costlier and less potent alternative. ${ }^{24}$ Amiloride, an epithelial sodium-channel blocker (not a mineralocorticoidreceptor antagonist), is another option and is used most commonly in primary aldosteronism. ${ }^{52}$

Table 2: Medications to be considered for add-on therapy to standard base three-drug regimen* for the treatment of resistant hypertension

$\begin{array}{llll}\text { Drug class; } & \text { Typical dosaget Comments } \\ \text { agent } & & \text { Half-lifet }\end{array}$

Antivolume (most useful if plasma renin activity $<0.65 \mathrm{ng} / \mathrm{mL}$ per hour) ${ }^{28}$

Mineralocorticoid-receptor antagonist

Eplerenone $\quad 50-100 \mathrm{mg}$ once daily or in $\quad 4-6 \mathrm{~h} \quad$ Reduced risk of cardiovascular-related hospital admission (RR $0.62,95 \% \mathrm{Cl} 0.52-$

$\begin{array}{lll}\text { two divided doses } & 0.74 \text { ) and total mortality (RR } 0.79,95 \% \mathrm{Cl} 0.66-0.95) \text { among patients with heart } \\ \text { failure and reduced ejection fraction (see Table } 3 \text { ). }{ }^{29} \text { Patients need to be monitore }\end{array}$

Spironolactone $\quad 25-50 \mathrm{mg}$ once daily for $\quad 80 \mathrm{~min}$ for hyperkalemia and prerenal failure. Spironolactone may cause painful primary resistant $\quad 10-20 \mathrm{~h}$ for gynecomastia, impotence, decreased libido or irregular menses, collectively hypertension; $25-200 \mathrm{mg} \quad$ active occurring in $5 \%-30 \%$ of patients. once daily for primary metabolites aldosteronism

Epithelial sodium-channel inhibitor

Amiloride 5-10 mg once daily or in 6-9 h Most commonly used as second- or third-line treatment for primary aldosteronism.

\begin{tabular}{llll} 
& two divided doses & Patients need to be monitored for hyperkalemia and renal failure. \\
\hline Loop diuretic & & \\
\hline Furosemide & $\begin{array}{l}40-120 \mathrm{mg} \text { daily in two or } \\
\text { three divided doses }\end{array}$ & $0.5-2 \mathrm{~h}$ & $\begin{array}{l}\text { Useful in patients with fluid overload states such as renal or heart failure. Patients } \\
\text { need to be monitored for electrolyte disturbances, ototoxicity and renal failure. }\end{array}$
\end{tabular}

$\alpha-1$ Adrenergic antagonist

$\begin{array}{llll}\text { Doxazosin } & 2-16 \mathrm{mg} \text { once daily } & 22 \mathrm{~h} & \begin{array}{l}\text { Dose at bedtime. Useful if benign prostatic hypertrophy is present. May cause } \\ \text { dizziness }(5 \%-20 \%), \text { orthostasis }(2 \%), \text { sedation }(5 \%) \text { or fluid retention }(7 \%) .\end{array} \\ \begin{array}{lll}\text { Dizziness and orthostasis may be the most prominent adverse effects with the first } \\ \text { dose. }\end{array}\end{array}$

Anti-renin (most useful if plasma renin activity $\geq 0.65 \mathrm{ng} / \mathrm{mL}$ per hour) ${ }^{28}$

$\beta$-Adrenergic antagonist

\begin{tabular}{|c|c|c|c|}
\hline Atenolol & 25-100 mg once daily & $6-7 \mathrm{~h}$ & \multirow{5}{*}{$\begin{array}{l}\text { See Table } 3 \text { for compelling indications. May cause bradycardia (3\%), heart block, } \\
\text { weight gain }(<1 \%) \text { or diabetes }(1 \%-3 \%) \text {. May aggravate acute heart failure, } \\
\text { asthma and severe peripheral vascular disease. Pharmacologic differences exist that } \\
\text { are of uncertain clinical significance: labetolol also blocks } \alpha-1 \text { and } \beta-2 \text { receptors, and } \\
\text { nebivolol has a vasodilatory, nitric oxide-potentiating action. Negative } \\
\text { chronotropic action is synergistic with non-dihydropyridine calcium-channel } \\
\text { blockers. Tachycardia may occur with abrupt withdrawal. }\end{array}$} \\
\hline Bisoprolol & $2.5-10 \mathrm{mg}$ daily & $9-12 \mathrm{~h}$ & \\
\hline Labetolol & $100-400$ mg twice daily & $6-8 \mathrm{~h}$ & \\
\hline Metoprolol & $\begin{array}{l}50-200 \mathrm{mg} \text { daily in two } \\
\text { divided doses }\end{array}$ & $3-9 h$ & \\
\hline Nebivolol & 5-20 mg once daily & $10-12 \mathrm{~h}$ & \\
\hline
\end{tabular}

Direct renin inhibitor

Aliskiren $\quad 150-300 \mathrm{mg}$ once daily $\quad 16-32 \mathrm{~h} \quad$ Patients need to be monitored for hyperkalemia. Do not use in combination with another renin-angiotensin system blocking agent in patients with diabetes because the risk of cardiovascular events and hyperkalemia is increased. ${ }^{40}$

Centrally acting $\alpha-2$ agonist

$\begin{array}{llcl}\text { Clonidine } & 0.1-0.4 \mathrm{mg} \text { twice daily } & 12-16 \mathrm{~h} & \begin{array}{l}\text { May cause sedation (10\%-30\%), dry mouth and eyes (30\%) or bradycardia (0.3\%). } \\ \text { Rebound hypertension occurs with abrupt discontinuation. Methyldopa can be used } \\ \text { in pregnant patients, but it has mild efficacy and, in rare circumstances, can cause a } \\ \text { lupus-like syndrome. }\end{array} \\ \text { Methyldopa } & \begin{array}{l}250-1000 \mathrm{mg} \text { daily in two } \\ \text { divided doses }\end{array} & 2 \mathrm{~h} & \end{array}$

Vasodilator (neither antivolume nor anti-renin)

\begin{tabular}{|c|c|c|c|}
\hline Hydralazine & $\begin{array}{l}25-100 \text { mg daily in two } \\
\text { divided doses }\end{array}$ & $2-8 h$ & $\begin{array}{l}\text { Indicated for use in black patients with systolic heart failure (in combination with } \\
\text { nitrates). Commonly used in pregnant patients because its safety has been } \\
\text { established. May exacerbate angina and cause palpitations }(5 \%) \text {, fluid retention } \\
(5 \%) \text { or drug-induced lupus }(5 \%-20 \%) \text {. }\end{array}$ \\
\hline Minoxidil & $\begin{array}{l}2.5-80 \mathrm{mg} \text { once daily or in } \\
\text { two divided doses }\end{array}$ & $3-4 h$ & $\begin{array}{l}\text { May cause tachycardia ( } 80 \%) \text {, fluid retention }(80 \%) \text {, hypertrichosis }(80 \%) \text {, } \\
\text { pericarditis or pericardial effusion }(3 \%) \text {. }\end{array}$ \\
\hline \multicolumn{4}{|c|}{$\begin{array}{l}\text { Note: } \mathrm{Cl}=\text { confidence interval, } \mathrm{RR}=\text { risk ratio. } \\
\text { *The standard regimen consists of a thiazide or nonthiazide diuretic (antivolume), angiotensin-converting-enzyme inhibitor or angiotensin-receptor blocker (anti-renin) and a } \\
\text { calcium-channel blocker (antivolume, usually of the dihydropyridine variety). Long-acting agents are preferred. } \\
\text { †Information on dosing is from Lexicomp (www.lexi.com). Please refer to the product monographs for information on adjustment of doses in the setting of renal or liver } \\
\text { dysfunction. } \\
\text { †A partial list of prototypical agents is provided. }\end{array}$} \\
\hline
\end{tabular}


Dramatic reductions in office-based blood pressure readings (usually $>20 \mathrm{~mm} \mathrm{Hg}$ ) with add-on spironolactone treatment were reported in an observational study. ${ }^{53}$ In an RCT involving 117 patients with resistant hypertension, the addition of spironolactone reduced daytime ambulatory systolic blood pressure by $9.3 \mathrm{~mm} \mathrm{Hg}$, compared with a reduction of $3.9 \mathrm{~mm} \mathrm{Hg}$ with placebo $(p<0.02) .{ }^{54}$ Corresponding reductions in office-based readings of systolic blood pressure were $14.6 \mathrm{~mm} \mathrm{Hg}$ and $8.1 \mathrm{~mm} \mathrm{Hg}(p=$ $0.01) .{ }^{54}$

\section{Empiric therapy with sequential nephron blockade versus sequential renin- angiotensin system blockade}

In a prospective, randomized, open-label trial involving 167 patients already taking irbesartan $(300 \mathrm{mg} / \mathrm{d})$, hydrochlorothiazide $(12.5 \mathrm{mg} / \mathrm{d})$ and amlodipine $(5 \mathrm{mg} / \mathrm{d})$, participants were randomly assigned to receive either sequential nephron blockade consisting of add-on therapy with lowdose diuretics $(25 \mathrm{mg}$ sprironolactone \pm 20 $40 \mathrm{mg}$ furosemide $\pm 5 \mathrm{mg}$ amiloride) or sequential renin-angiotensin system blockade $(5-10 \mathrm{mg}$ ramipril $\pm 5-10 \mathrm{mg}$ bisoprolol) for 12 weeks..$^{55}$ Renin profiling was not used in this study. Doses were adjusted or additional drugs added every four weeks. At 12 weeks, the mean 24-hour ambulatory blood pressure was lower in the

Table 3: Compelling indications for specific drug classes*

\begin{tabular}{|c|c|}
\hline Indication & Drug class \\
\hline Diabetes with nephropathy & $\begin{array}{l}\text { ACE inhibitor or angiotensin-receptor } \\
\text { blocker }^{30,31}\end{array}$ \\
\hline $\begin{array}{l}\text { Nondiabetic chronic kidney disease } \\
\text { with proteinuria }\end{array}$ & $\begin{array}{l}\text { ACE inhibitor or angiotensin-receptor } \\
\text { blocker if patient is ACE-intolerant }\end{array}$ \\
\hline Coronary artery disease & $\begin{array}{l}\text { ACE inhibitor or angiotensin-receptor } \\
\text { blocker; }_{i}^{33,34} \beta \text {-blocker }{ }^{35}\end{array}$ \\
\hline $\begin{array}{l}\text { Heart failure with reduced ejection } \\
\text { fraction }\end{array}$ & $\begin{array}{l}\text { ACE inhibitor or angiotensin-receptor } \\
\text { blocker; }{ }^{36,37} \beta \text {-blocker; }{ }^{38} \\
\text { mineralocorticoid-receptor } \\
\text { antagonist given to select patients } \\
\text { depending on their clinical } \\
\text { presentation (recent hospital } \\
\text { admission because of a cardiovascular } \\
\text { event, acute myocardial infarction, } \\
\text { elevated level of B-type natriuretic } \\
\text { peptide or N-terminal pro-brain } \\
\text { natriuretic peptide, or New York } \\
\text { Heart Association class II-IV heart } \\
\text { failure }\end{array}$ \\
\hline $\begin{array}{l}\text { Previous stroke or transient } \\
\text { ischemic attack }\end{array}$ & $\begin{array}{l}\text { Combination of an ACE inhibitor and } \\
\text { a diuretic }{ }^{39}\end{array}$ \\
\hline
\end{tabular}

Note: $\mathrm{ACE}=$ angiotensin-converting enzyme.

*According to the Canadian Hypertension Education Program ${ }^{11}$ these drugs are considered

to have compelling indications for use because of their ability to reduce mortality,

cardiovascular morbidity or renal morbidity. group given sequential diuretic treatment (129/79 mm Hg v. $139 / 83 \mathrm{~mm} \mathrm{Hg}$; mean difference $-10 /-4 \mathrm{~mm} \mathrm{Hg} ; p<0.01)$. These results show that empiric diuretic therapy is more likely than sequential renin-angiotensin system blockade to achieve blood pressure control in patients already receiving a standard base regimen.

\section{Referral to a specialty clinic}

In uncontrolled observational studies, referral to a hypertension specialist increased the proportion of patients with controlled blood pressure from $0 \%-18 \%$ to $52 \%-53 \%{ }^{1,8}$

\section{Application in clinical practice}

Box 3 illustrates the treatment of a patient with resistant hypertension.

\section{What other treatment options are available?}

Renal sympathetic denervation is a catheter-based percutaneous procedure (currently approved for use in Canada, Europe and elsewhere) that uses radiofrequency energy to ablate the afferent and efferent renal nerves (located in or adjacent to the arterial adventitial layer). The denervation procedure thereby targets elevated activity of the sympathetic nervous system and is based conceptually on surgical sympathectomy, a procedure used to treat resistant hypertension in the pre-antihypertensive era $(\sim 1920$ to the 1950s). ${ }^{56}$ Reductions in central sympathetic outflow, renal vasoconstriction, renin-angiotensin activation, and sodium and water retention are the putative mechanisms involved in lowering blood pressure.

In a 6-month RCT involving 106 patients with resistant hypertension (systolic blood pressure $\geq 160 \mathrm{~mm} \mathrm{Hg}$ or $\geq 150 \mathrm{~mm} \mathrm{Hg}$ in patients with diabetes), blood pressure was reduced by $33 / 12 \mathrm{~mm} \mathrm{Hg}(p<0.0001)$ more in patients who underwent renal denervation than in the control group. ${ }^{57}$ Some nonrandomized studies have reported that renal denervation was associated with improvements in surrogate outcomes, such as sympathetic activity, left ventricular hypertrophy, glycemic control and diastolic dysfunction. ${ }^{58-61}$

Some of the reported criticisms of these studies are the lack of outcome data for 24-hour ambulatory blood pressure measurement and the lack of a sham procedure (catheterization without renal denervation) in the control group. ${ }^{58,62}$ In these prelininary studies, reductions in out-of-office blood pressure were much lower than the reductions in manual office-based readings, raising the possibil- 
ity that a large portion of the reduction in blood pressure was unrelated to the procedure. ${ }^{58} \mathrm{~A}$ recently published, 6-month, single-blind, randomized, sham-controlled trial involving 535 patients reported no difference in the reduction of blood pressure between the renal denervation group and the control group (change in 24-hour ambulatory systolic pressure of $-6.8 \mathrm{~mm} \mathrm{Hg}$ v. $-4.8 \mathrm{~mm} \mathrm{Hg}, p=0.98) .{ }^{63}$ Office systolic blood pressure was also not different between the groups (difference $2.4 \mathrm{~mm} \mathrm{Hg}, p=$ $0.26)$.

These findings cast uncertainty over the future use of renal denervation, and some manufacturers of denervation catheters have stopped any further studies pending internal reviews. The findings also emphasize the importance of performing careful, controlled assessment, including optimal outcome assessment, before the widespread adoption of new technologies. Although the results could be explained theoretically by incomplete or ineffective renal denervation, improved adherence by patients to background drug therapy, regression to the mean, a "placebo" effect of the sham procedure, and additional factors are as or more likely. ${ }^{64}$ Overall, renal denervation is of uncertain efficacy at this time, and its use cannot be recommended outside of ongoing and future research trials.

\section{Unanswered questions}

The nonpharmacologic and pharmacologic management of resistant hypertension is largely based on consensus recommendations by experts. Algorithm-based approaches, such as renin profiling to guide drug selection, require further validation. Comparative effectiveness RCTs are needed to identify the most efficacious treatment regimens.

New drugs designed to counteract vasoconstriction, fibrosis and inflammation, to inhibit aldosterone synthesis or to reduce arterial stiffness are under investigation; however, early efficacy results for many of these drugs have been disappointing, and unacceptable adverse events

\section{Box 3: Applying the results of this review in clinical practice}

The following real case illustrates one approach to managing resistant hypertension. Alternative approaches are possible, and patient response may vary.

A 60-year-old woman with a history of diabetes, obesity, sleep apnea (treated with continuous positive airway pressure) and dyslipidemia is referred because of uncontrolled blood pressure. Her antihypertensive drugs are $20 \mathrm{mg}$ lisinopril twice daily, $40 \mathrm{mg}$ furosemide daily and $360 \mathrm{mg}$ diltiazem (long-acting) daily. Other medications include insulin, atorvastatin, acetylsalicylic acid and metformin. The patient is a nonsmoker and does not consume alcohol. She follows a diet with no added salt and walks for 30 minutes three times a week. Her body mass index (BMI) is 34.1, and she weighs $78.7 \mathrm{~kg}$. Her most recent hemoglobin $A_{1 c}$ concentration was $8.6 \%$, and she is followed by a diabetologist. Her serum creatinine level is $81 \mu \mathrm{mol} / \mathrm{L}$, serum potassium level $5.0 \mathrm{mmol} / \mathrm{L}$ and low-density lipoprotein cholesterol $1.65 \mathrm{mmol} / \mathrm{L}$. Her urinary albumin-to-creatinine ratio is normal, as were two previous 24-hour urine cortisol levels, the thyroid stimulating hormone level and the calcium level.

The automated blood pressure readings taken in the office are $165 / 78 \mathrm{~mm} \mathrm{Hg}$ on average, and her systolic readings at home are frequently higher than $160 \mathrm{~mm} \mathrm{Hg}$. Twenty-four hour ambulatory blood pressure monitoring is offered to assess out-of-office readings more accurately, but the patient prefers to use her home blood pressure monitor. She is counselled on health behaviour modifications, including recommendations to lose weight and to increase her level of aerobic exercise to 60 minutes of walking most days of the week. Measurement of aldosterone and renin levels is requested.

Two weeks later, her average blood pressure is $158 / 67 \mathrm{~mm} \mathrm{Hg}$ in the office and $156 / 78 \mathrm{~mm} \mathrm{Hg}$ (over 12 measurements) at home. The need for health behaviour modifications is reinforced. Treatment with lisinopril and furosemide is replaced by a long-acting, once-daily combination preparation (8 $\mathrm{mg}$ perindopril and $2.5 \mathrm{mg}$ indapamide) to reduce the pill burden and to simplify the dosing schedule.

One month later, her average blood pressure is $151 / 60 \mathrm{~mm} \mathrm{Hg}$ in the office. Amlodipine is prescribed ( $5 \mathrm{mg}$ once daily for two weeks and $10 \mathrm{mg}$ once daily at bedtime thereafter), and diltiazem is stopped. (Switching from a dihydropyridine to a nondihydropyridine calcium-channel blocker eliminates the possiblility of excessive negative chronotropic action when a $\beta$-blocker is prescribed next).

After another month, her blood pressure levels are unchanged. Her aldosterone level is low normal (102 pmol/L), her renin level is over 10-fold above the laboratory normal limit, and her pulse rate is 85 beats/min. Because of the high renin level, the advantages, disadvantages and risks of screening for renal artery stenosis are discussed with the patient. She elects to undergo a renal scan with captopril (after a 48-hour hold of the ACE inhibitor). The scan is normal. Treatment with a long-acting anti-renin drug (5 mg bisoprolol once daily) is added.

Her average blood pressure in the office is $126 / 54 \mathrm{~mm} \mathrm{Hg}$ one month later and $125 / 51 \mathrm{~mm} \mathrm{Hg}$ two months later. Her average blood pressure levels at home are similar. She weighs $77.4 \mathrm{~kg}$ and has a BMI of 34.0. The importance of optimizing health behaviours is reinforced at her final visit before she is referred back to the care of her family physician. 
have occurred. ${ }^{65}$ Device-based treatments are under active and intense investigation: renal sympathetic denervation and carotid baroreflex stimulation are the furthest along the development path. Increased uptake will likely occur if the long-term safety and efficacy of these treatments are established.

\section{References}

1. Calhoun DA, Jones D, Textor S, et al. Resistant hypertension: diagnosis, evaluation and treatment: a scientific statement from the American Heart Association Professional Education Committee of the Council for High Blood Pressure Research. Hypertension 2008;51:1403-19.

2. Williams B. Resistant hypertension: an unmet treatment need. Lancet 2009;374:1396-8.

3. McAlister FA, Wilkins K, Joffres M, et al. Changes in the rates of awareness, treatment and control of hypertension in Canada over the past two decades. CMAJ 2011;183:1007-13.

4. Robitaille C, Dai S, Waters C, et al. Diagnosed hypertension in Canada: incidence, prevalence and associated mortality. CMAJ 2012;184:E49-56

5. Gee ME, Bienek A, McAlister FA, et al. Factors associated with lack of awareness and uncontrolled high blood pressure among Canadian adults with hypertension. Can J Cardiol 2012;28:375-82.

6. McAdam-Marx C, Ye X, Sung JC, et al. Results of a retrospective, observational pilot study using electronic medical records to assess the prevalence and characteristics of patients with resistant hypertension in an ambulatory care setting. Clin Ther 2009;31:1116-23.

7. Persell SD. Prevalence of resistant hypertension in the United States, 2003-2008. Hypertension 2011;57:1076-80.

8. Garg JP, Elliot WJ, Folker A, et al. Resistant hypertension revisited: a comparison of two university-based cohorts. Am J Hypertens 2005; 18:619-26

9. Yakovlevitch M, Black HR. Resistant hypertension in a tertiary care clinic. Arch Intern Med 1991;151:1786-92.

10. Pierdomenico SD, Lapenna D, Bucci A, et al. Cardiovascular outcome in treated hypertensive patients with responder, masked, false-resistant and true-resistant hypertension. Am J Hypertens 2005; $18: 1422-8$

11. Dasgupta K, Quinn RR, Zarnke KB, et al. The 2014 Canadian Hypertension Education Program recommendations for blood pressure measurement, diagnosis, assessment of risk, prevention, and treatment of hypertension. Can J Cardiol 2014;30:485-501.

12. White LH, Bradley TD. Role of nocturnal rostral fluid shift in the pathogenesis of obstructive and central sleep apnea. J Physiol 2013;591:1179-93.

13. Rossi GP, Seccia TM, Maniero C, et al. Drug-related hypertension and resistance to antihypertensive treatment. $J$ Hypertens 2011;29:2295-309.

14. Funder JW, Carey RM, Fardella C, et al. Case detection, diagnosis, and treatment of patients with primary aldosteronism: an Endocrine Society clinical practice guideline. J Clin Endocrinol Metab 2008;93:3266-81.

15. Trinquart L, Mounier-Vehier C, Sapoval M, et al. Efficacy of revascularization for renal artery stenosis caused by fibromuscular dysplasia: a systematic review and meta-analysis. Hypertension 2010;56:525-32.

16. Cooper CJ, Murphy TP, Cutlip DE, et al. Stenting and medical therapy for atherosclerotic renal-artery stenosis. N Engl J Med 2014; 370:13-22.

17. Raber W, Raffesberg W, Bischof M, et al. Diagnostic efficacy of unconjugated plasma metanephrines for the detection of pheochromocytoma. Arch Intern Med 2000;160:2957-63.

18. de la Sierra A, Segura J, Banegas JR, et al. Clinical features of 8295 patients with resistant hypertension classified on the basis of ambulatory blood pressure monitoring. Hypertension 2011;57:898-902.

19. Pedrosa RP, Drager LF, Gonzaga CC, et al. Obstructive sleep apnea: the most common secondary cause of hypertension associated with resistant hypertension. Hypertension 2011;58:811-7.

20. Ruttanaumpawan P, Nopmaneejumruslers C, Logan AG, et al Association between refractory hypertension and obstructive sleep apnea. J Hypertens 2009;27:1439-45.

21. Rossi GP. Prevalence and diagnosis of primary aldosteronism. Curr Hypertens Rep 2010;12:342-8.

22. Rossi GP, Bernini G, Caliumi C. A prospective study of the prevalence of primary aldosteronism in 1,125 hypertensive patients. J Am Coll Cardiol 2006;48:2293-300.

23. Calhoun DA. Obstructive sleep apnea and hypertension. Curr Hypertens Rep 2010;12:189-95.
24. Sica DA. What is the role of aldosterone excess in resistant hypertension and how should it be investigated and treated? Curr Cardiol Rep 2011;13:520-6.

25. Korner PI. Essential hypertension and its causes. Neural and nonneural mechanisms. New York: Oxford University Press; 2007.

26. Katholi RE, Rocha-Singh KJ. The role of renal sympathetic nerves in hypertension: Has percutaneous renal denervation refocused attention on their clinical significance? Prog Cardiovasc Dis 2009;52:243-8.

27. Fisher JP, Paton JF. The sympathetic nervous system and blood pressure in humans: implications for hypertension. J Hum Hypertens 2012;26:463-75.

28. Laragh J. Laragh's lessons in pathophysiology and clinical pearls for treating hypertension. Am J Hypertens 2001;14:491-503.

29. Hu LJ, Chen YQ, Deng SB, et al. Additional use of an aldosterone antagonist in patients with mild to moderate chronic heart failure: a systematic review and meta-analysis. $\mathrm{Br} J$ Clin Pharmacol 2013;75:1202-12.

30. Wu HY, Huang JW, Lin HJ, et al. Comparative effectiveness of renin-angiotensin system blockers and other antihypertensive drugs in patients with diabetes: systematic review and bayesian network meta-analysis. BMJ 2013;347:f6008.

31. Lv J, Perkovic V, Foote CV, et al. Antihypertensive agents for preventing diabetic kidney disease. Cochrane Database Syst Rev 2012;12:CD004136.

32. Maione A, Navaneethan SD, Graziano G, et al. Angiotensinconverting enzyme inhibitors, angiotensin-receptor blockers and combined therapy in patients with micro- and macroalbuminuria and other cardiovascular risk factors: a systematic review of randomized controlled trials. Nephrol Dial Transplant 2011;26: 2827-47.

33. Al-Mallah MH, Tleyjeh IM, Abdel-Latif AA, et al. Angiotensinconverting enzyme inhibitors in coronary artery disease and preserved left ventricular systolic function: a systematic review and meta-analysis of randomized controlled trials. J Am Coll Cardiol 2006; 47:1576-83.

34. Yusuf S, Teo KK, Poque J, et al; ONTARGET Investigators. Telmisartan, ramipril, or both in patients at high risk for vascular events. N Engl J Med 2008;358:1547-59.

35. Freemantle N, Cleland J, Young P, et al. Beta-blockade after myocardial infarction: systematic review and meta-regression analysis. BMJ 1999;318:1730-7.

36. Flather MD, Yusuf S, Kober L, et al. Long-term ACE-inhibitor therapy in patients with heart failure or left-ventricular dysfunction: a systematic overview of data from individual patients. Lancet 2000;355:1575-81.

37. Verdecchia P, Angeli F, Cavallini C, et al. Blood pressure reduction and renin-angiotensin system inhibition for prevention of congestive heart failure: a meta-analysis. Eur Heart $J$ 2009;30: 679-88.

38. Foody JM, Farrell MH, Krumholz HM. Beta-blocker therapy in heart failure: scientific review. JAMA 2002;287:883-9.

39. PROGRESS Collaborative Group. Randomised trial of a perindopril-based blood-pressure-lowering regimen among 6,105 individuals with previous stroke or transient ischaemic attack. Lancet 2001:358:1033-41.

40. Parving HH, Brenner BM, McMurray JJ, et al. Cardiorenal end points in a trial of aliskiren for type 2 diabetes. N Engl J Med 2012; 367:2204-13.

41. Dimeo F, Pagonas N, Seibert F, et al. Aerobic exercise reduces blood pressure in resistant hypertension. Hypertension 2012; 60:653-8.

42. Hermida RC, Ayala DE, Calvo C, et al. Effects of time of day of treatment on ambulatory blood pressure pattern of patients with resistant hypertension. Hypertension 2005;46:1053-9.

43. Hermida RC, Ayala DE, Mojón A, et al. Influence of circadian time of hypertension treatment on cardiovascular risk: results of the MAPEC study. Chronobiol Int 2010;27:1629-51.

44. Padwal R. Applying the 2005 Canadian Hypertension Education Program recommendations: 3 . Lifestyle modifications to prevent and treat hypertension. CMAJ 2005;173:749-51.

45. Pimenta E, Gaddam KK, Oparil S, et al. Effects of dietary sodium reduction on blood pressure in subjects with resistant hypertension: results from a randomized trial. Hypertension 2009;54:475-81.

46. Lozano L, Tovar JL, Sampol G, et al. Continuous positive airway pressure treatment in sleep apnea patients with resistant hypertension: a randomized, controlled trial. J Hypertens 2010;28:2161-8.

47. Egan BM, Basile JN, Rehman SU, et al. Plasma renin testguided drug treatment algorithm for correcting patients with treated but uncontrolled hypertension: a randomized controlled trial. Am J Hypertens 2009;22:792-801.

48. Olson N, DeJongh B, Hough A, et al. Plasma renin activity-guided strategy for the management of hypertension. Pharmacotherapy 2012;32:446-55. 
49. Preston RA, Materson BJ, Reda DJ. Age-race subgroup compared with renin profile as predictors of blood pressure response to antihypertensive therapy. Department of Veterans Affairs Cooperative Study Group on Antihypertensive Agents. JAMA 1998;280:1168-72.

50. Turner ST, Schwartz GL, Chapman AB, et al. Plasma renin activity predicts blood pressure responses to beta-blocker and thaizide diuretic as monotherapy and add-on therapy for hypertension. Am J Hypertens 2010;23:1014-22.

51. Handler J. Overlapping spironolactone dosing in primary aldosteronism and resistant essential hypertension. J Clin Hypertens (Greenwich) 2012;14:732-4.

52. Eide IK, Torjesen PA, Drolsum A, et al. Low-renin status in therapy-resistant hypertension: a clue to efficient treatment. $J$ Hypertens 2004;22:2217-26.

53. Goodfriend TL. Treating resistant hypertension with a neglected old drug. Hypertension 2007;49:763-4.

54. Václavik J, Sedlák R, Plachy M, et al. Addition of spironolactone in patients with resistant arterial hypertension (ASPIRANT): a randomized, double-blind, placebo-controlled trial. Hypertension 2011;57:1069-75

55. Bobrie G, Frank M, Azizi M, et al. Sequential nephron blockade versus sequential renin-angiotensin system blockade in resistant hypertension. J Hypertens 2012;30:1656-64.

56. Esunge PM. From blood pressure to hypertension: the history of research. J R Soc Med 1991;84:621.

57. Esler MD, Krum H, Sobotka PA, et al. Renal sympathetic denervation in patients with treatment-resistant hypertension (the Symplicity HTN-2 Trial): a randomised controlled trial. Lancet 2010;376:1903-9.

58. Persu A, Renkin J, Thijs L, et al. Renal denervation ultima ratio or standard in treatment-resistant hypertension. Hypertension 2012 60:596-606

59. Mahfoud F, Schlach M, Kindermann I, et al. Effect of renal sympathetic denervation on glucose metabolism in patients with resistant hypertension: a pilot study. Circulation 2011;123: 1940-6.

60. Hering D, Lambert EA, Marusic P, et al. Substantial reduction in single sympathetic nerve firing after renal denervation in patients with resistant hypertension. Hypertension 2013;61:457-64

61. Brandt MC, Mahfoud F, Reda S, et al. Renal sympathetic denervation reduces left ventricular hypertrophy and improves cardiac function in patients with resistant hypertension. J Am Coll Cardiol 2012;59:901-9.

62. Khan NA, Herman RJ, Quinn RR, et al. Renal denervation therapy for the treatment of resistant hypertension: a position statement by the Canadian Hypertension Education Program. Can J Cardiol 2014;30:16-21.

63. Bhatt DL, Kandzari DE, O'Neill WW, et al. A controlled trial of renal denervation for resistant hypertension. N Engl J Med 2014; 370:1393-401.

64. Messerli FH, Bangalore S. Renal denervation for resistant hypertension? N Engl J Med 2014;370:1454-7.

65. Laurent S, Schlaich M, Esler M. New drugs, procedures, and devices for hypertension. Lancet 2012;380:591-600.

Affiliations: Department of Medicine (Padwal), University of Alberta, Edmonton, Alta.; Alberta Diabetes Institute (Padwal), Edmonton, Alta.; Division of Cardiology (Rabkin), Department of Medicine (Rabkin, Khan), University of British Columbia, Vancouver, BC; Center for Health Evaluation and Outcome Sciences (Khan), Vancouver, BC

Contributors: Raj Padwal and Nadia Khan wrote the initial draft of the manuscript. All of the authors critically revised the manuscript, approved the final version submitted for publication and agreed to act as guarantors of the work. 